\title{
Deprivation indicators as predictors of life events 1981-1992 based on the UK ONS longitudinal study
}

Andrew Sloggett, Heather Joshi

\begin{abstract}
Studyobjective-Toinvestigate the association between the level of social deprivation in electoral wards and various life events. Life events include mortality, self reported long term illness, and for women: stillbirth, underweight birth, birth while a teenager, and sole registered birth. Associations with area deprivation are tested before and after allowing for levels of personal deprivation.

Design-Prospective census follow up using the Office for National Statistics Longitudinal Study.

Setting-England and Wales.

Participants-A random sample of more than 300000 people enumerated at the 1981 census, and aged 10 to 64 in 1981 . Some analyses are necessarily restricted to certain age/sex groups.

Outcome measures-Several outcomes in the decade 1981-1992 are investigated: risk of premature death (before age 70 , all cause), risk of long term limiting illness in 1991 , and risk of inauspicious fertility outcomes in women.
\end{abstract}

Main results-Without adjusting for personal circumstances all outcomes, except risk of stillbirth, show a clear, significant, and approximately linear association with social deprivation of ward of residence in 1981. Associations are much stronger for outcomes where a greater "social" component can be construed (teenage birth, sole registered birth) than for outcomes that are probably more physiologically determined (mortality, stillbirth, low birth weight). When adjustment is made for personal disadvantage the simple associations with local area deprivation are all attenuated, especially for those living in the more deprived areas.

Conclusions-A variety of adverse or "inauspicious" life events show association with residence in more deprived areas. These are particularly strong for

Accepted for publication 28 July 1997

Table 1 Outcomes investigated

Mortality

Stillbirth

Low birth weight

Sole registration

Teenage birth

Long term limiting illness
Risk of premature death 1983-1992 for those aged 20 to 64 in 1981 Risk of any stillbirth 1981-1992 for women aged 15 to 39 in 1981 Risk of child born with birth weight less than $2500 \mathrm{~g} \mathrm{1981-1992}$ for women aged 15 to 39 in 1981

Risk of any sole registered birth, when aged 20+, 1981-1992 for women aged 15 to 39 in 1981 (excluding those becoming mothers before age 20)

Risk of birth (live or still) while still a teenager 1981-1991 for women aged 10 to 19 in 1981

Risk of self reporting a long term limiting illness in the 1991 census for those aged $20-64$ in 1981 teenage birth and sole registered birth, but are also stronger for long term illness than mortality. These associations seem to be largely because residence in more deprived areas is associated with personal disadvantage, which is more damaging to life chances than area of residence. For some outcomes there is evidence that the personally disadvantaged fare less well if living in relatively advantaged areas, than if living in more homogenously deprived areas.

\section{(7 Epidemiol Community Health 1998;52:228-233)}

Census indicators of deprivation can be used to add a geographical dimension to the explanation of health inequalities ${ }^{1}$ and in the allocation of health service resources. ${ }^{23}$ As the census does not directly identify people living on low incomes, census indicators of the social profile of small areas are sometimes used as a proxy for information about the economic circumstances of inhabitants. ${ }^{4}$ However, the information the census does collect on individual employment and household circumstances, where it is available for research purposes, is likely to be more precise than any ecological measure in identifying those households likely to be poor. ${ }^{5}$ The shortcomings of census indicators for making meaningful nationwide comparisons have been noted. ${ }^{67}$

That indicators of deprivation are available at a local level does not necessarily mean that there is a spatial element to the experience of poverty. It is however widely suggested that "poor places" are not only socially adverse environments, but strike at the health status of even the non-poor inhabitants. McCormick and Philo ${ }^{6}$ and Macintyre et $a l^{8}$ argue, quite plausibly, that the residents of many poor communities suffer from a combination of poor opportunities, poor services, sometimes high crime, low morale and stigma, which compounds the individual's experience of poverty.

Previous work by the present authors, also using the Longitudinal Study, confirmed the clear association of premature mortality to the social deprivation score of the electoral ward of residence. ${ }^{9}$ This "deprivation effect" was however largely accounted for by the extent of individual or household level disadvantage. This paper reassesses mortality outcome using a longer period of follow up, and also investigates other outcomes.

These new outcomes include self reported long term limiting illness (LLI) and a selection 
Table 2 Associations between deprivation score and various outcomes, before and after adjustment for personal or household circumstances

\begin{tabular}{|c|c|c|c|c|c|c|c|c|c|c|c|c|c|c|c|c|}
\hline \multirow[b]{2}{*}{ Model } & \multicolumn{2}{|c|}{$\begin{array}{l}\text { Male } \\
\text { mortality }\end{array}$} & \multicolumn{2}{|c|}{$\begin{array}{l}\text { Female } \\
\text { mortality }\end{array}$} & \multicolumn{2}{|c|}{ Male LLI } & \multicolumn{2}{|c|}{ Female LLI } & \multicolumn{2}{|c|}{ Stillbirth } & \multicolumn{2}{|c|}{$\begin{array}{l}\text { Low birth } \\
\text { weight }\end{array}$} & \multicolumn{2}{|c|}{ Teenage birth } & \multicolumn{2}{|c|}{$\begin{array}{l}\text { Sole } \\
\text { registration }\end{array}$} \\
\hline & $O R$ & $95 \% C I$ & $O R$ & $95 \% C I$ & $O R$ & $95 \% C I$ & $O R$ & $95 \% C I$ & $O R$ & $95 \% C I$ & $O R$ & $95 \% C I$ & $O R$ & $95 \% C I$ & $O R$ & $95 \% C I$ \\
\hline 1 Deprivation score 1981 & 1.08 & $\begin{array}{l}1.06 \\
1.09\end{array}$ & 1.09 & $\begin{array}{l}1.07 \\
1.11\end{array}$ & 1.17 & $\begin{array}{l}1.16 \\
1.18\end{array}$ & 1.17 & $\begin{array}{l}1.16 \\
1.18\end{array}$ & 1.03 & $\begin{array}{l}0.96 \\
1.10\end{array}$ & 1.07 & $\begin{array}{l}1.05 \\
1.10\end{array}$ & 1.26 & $\begin{array}{l}1.23 \\
1.28\end{array}$ & 1.28 & $\begin{array}{l}1.25 \\
1.32\end{array}$ \\
\hline $\begin{array}{l}\text { Change in odds best to } \\
\text { worst }\end{array}$ & 1.80 & & 1.99 & & 3.47 & & 3.43 & & 1.27 & & 1.76 & & 6.23 & & 7.37 & \\
\hline 2 Deprivation score 1981 & 1.02 & $\begin{array}{l}1.00 \\
1.03\end{array}$ & 1.04 & $\begin{array}{l}1.02 \\
1.06\end{array}$ & 1.08 & $\begin{array}{l}1.07 \\
1.09\end{array}$ & 1.09 & $\begin{array}{l}1.08 \\
1.11\end{array}$ & 1.00 & $\begin{array}{l}0.93 \\
1.08\end{array}$ & 1.04 & $\begin{array}{l}1.02 \\
1.07\end{array}$ & 1.11 & $\begin{array}{l}1.09 \\
1.14\end{array}$ & 1.12 & $\begin{array}{l}1.09 \\
1.15\end{array}$ \\
\hline \multicolumn{17}{|l|}{$\begin{array}{l}\text { Personal circumstances } \\
\text { 1981: }\end{array}$} \\
\hline Unemployed & 1.46 & $\begin{array}{l}1.37 \\
1.57\end{array}$ & 1.51 & $\begin{array}{l}1.29 \\
1.76\end{array}$ & 2.07 & $\begin{array}{l}1.96 \\
2.18\end{array}$ & 2.43 & $\begin{array}{l}2.23 \\
2.64\end{array}$ & 0.93 & $\begin{array}{l}0.56 \\
1.54\end{array}$ & 1.39 & $\begin{array}{l}1.23 \\
1.59\end{array}$ & & & 2.45 & $\begin{array}{l}2.13 \\
2.83\end{array}$ \\
\hline Housewife /other & 1.52 & $\begin{array}{l}1.34 \\
1.71\end{array}$ & 1.45 & $\begin{array}{l}1.35 \\
1.55\end{array}$ & 1.54 & $\begin{array}{l}1.39 \\
1.71\end{array}$ & 1.45 & $\begin{array}{l}1.40 \\
1.51\end{array}$ & 1.07 & $\begin{array}{l}0.79 \\
1.44\end{array}$ & 0.87 & $\begin{array}{l}0.79 \\
0.96\end{array}$ & & & 1.27 & $\begin{array}{l}1.10 \\
1.46\end{array}$ \\
\hline Social class $4 / 5$ & 1.10 & $\begin{array}{l}1.04 \\
1.16\end{array}$ & 1.13 & $\begin{array}{l}1.05 \\
1.23\end{array}$ & 1.27 & $\begin{array}{l}1.22 \\
1.32\end{array}$ & 1.17 & $\begin{array}{l}1.11 \\
1.23\end{array}$ & 1.25 & $\begin{array}{l}0.88 \\
1.80\end{array}$ & 1.04 & $\begin{array}{l}0.93 \\
1.17\end{array}$ & & & 1.33 & $\begin{array}{l}1.15 \\
1.53\end{array}$ \\
\hline Not owner-occupier & 1.29 & $\begin{array}{l}1.22 \\
1.35\end{array}$ & 1.24 & $\begin{array}{l}1.17 \\
1.32\end{array}$ & 1.31 & $\begin{array}{l}1.26 \\
1.37\end{array}$ & 1.35 & $\begin{array}{l}1.30 \\
1.40\end{array}$ & 1.10 & $\begin{array}{l}0.84 \\
1.44\end{array}$ & 1.15 & $\begin{array}{l}1.06 \\
1.25\end{array}$ & 2.34 & $\begin{array}{l}2.16 \\
2.55\end{array}$ & 2.19 & $\begin{array}{l}1.94 \\
2.47\end{array}$ \\
\hline No car access & 1.29 & $\begin{array}{l}1.22 \\
1.36\end{array}$ & 1.33 & $\begin{array}{l}1.25 \\
1.42\end{array}$ & 1.37 & $\begin{array}{l}1.32 \\
1.43\end{array}$ & 1.41 & $\begin{array}{l}1.35 \\
1.46\end{array}$ & 1.20 & $\begin{array}{l}0.90 \\
1.59\end{array}$ & 1.15 & $\begin{array}{l}1.05 \\
1.26\end{array}$ & 1.63 & $\begin{array}{l}1.50 \\
1.77\end{array}$ & 1.81 & $\begin{array}{l}1.62 \\
2.03\end{array}$ \\
\hline 3 Gradient for score $>4^{\star}$ & 1.00 & $\begin{array}{l}0.97 \\
1.04\end{array}$ & 0.99 & $\begin{array}{l}0.95 \\
1.03\end{array}$ & 1.02 & $\begin{array}{l}1.00 \\
1.05\end{array}$ & 1.04 & $\begin{array}{l}1.01, \\
1.06\end{array}$ & $\begin{array}{l}\mathrm{N} / \\
\mathrm{A}\end{array}$ & & 1.02 & $\begin{array}{l}0.97 \\
1.08\end{array}$ & 1.02 & $\begin{array}{l}0.97 \\
1.06\end{array}$ & 1.10 & $\begin{array}{l}1.04 \\
1.16\end{array}$ \\
\hline \multicolumn{17}{|l|}{$\chi^{2}$ change in model $(\mathrm{df}): \dagger$} \\
\hline $\begin{array}{l}\text { Inclusion of deprivation } \\
\text { score }\end{array}$ & $\begin{array}{l}128(1 \\
\mathrm{p}<0 .\end{array}$ & $\begin{array}{l}1) \\
001\end{array}$ & $\begin{array}{l}219(1 \\
\mathrm{p}<0.0\end{array}$ & $\begin{array}{l}\text { 1) } \\
001\end{array}$ & $\begin{array}{l}1037 \\
p<0 .\end{array}$ & $\begin{array}{l}7(1) \\
.001\end{array}$ & $\begin{array}{l}1040 \\
p<0 .\end{array}$ & $\begin{array}{l}(1) \\
001\end{array}$ & $\begin{array}{l}1(1) \\
p>0.3\end{array}$ & 30 & $\begin{array}{l}47(1) \\
p<0.0\end{array}$ & 0 & $\begin{array}{l}548(1 \\
p<0.0\end{array}$ & $\begin{array}{l}\text { 1) } \\
001\end{array}$ & $\begin{array}{l}331(1 \\
\mathrm{p}<0.0\end{array}$ & $\begin{array}{l}\text { 1) } \\
001\end{array}$ \\
\hline + Inclusion of personal & $463(5$ & & $329(5$ & & 1774 & $4(5)$ & 1491 & & $5(5)$ & & $71(5)$ & & $739(2$ & & $608(5$ & \\
\hline circumstances & $\mathrm{p}<0$ & & $\mathrm{p}<0.0$ & & $\mathrm{p}<0$. & 001 & $\mathrm{p}<0$ & 001 & $\mathrm{p}>0.3$ & 300 & $\mathrm{p}<0$. & 001 & $\mathrm{p}<0.0$ & 001 & $\mathrm{p}<0.0$ & 001 \\
\hline + Inclusion of separate & $1(2)$ & & $10(2)$ & & $26(2)$ & & $24(2)$ & & $\mathrm{N} / \mathrm{A}$ & & $8(2)$ & & $40(2)$ & & $2(2)$ & \\
\hline gradient & $\mathrm{p}>0.5$ & 500 & $\mathrm{p}=0.0$ & 007 & $\mathrm{p}<0$ & .001 & $\mathrm{p}<0$. & 001 & & & $\mathrm{p}=0 . \mathrm{C}$ & 018 & $\mathrm{p}<0.0$ & 001 & $\mathrm{p}>0.3$ & 300 \\
\hline $\mathrm{n}=$ & 1337 & 792 & 1376 & 674 & 1169 & 958 & 1248 & 368 & 8083 & & 8083 & & 3364 & & 8051 & \\
\hline
\end{tabular}

Model details: All models adjusted for age and north/south zone. Mortality models further adjusted for time period 83-87, 88-92. Persons classified as permanently sick or disabled in 1981 are absent throughout.

${ }^{\star}$ Calculated by including the gradient term for score $>4$ and a term dichotomising the deprivation score (not shown). $\dagger$ Incremental improvement from base model of age, zone, time period.

of "adverse" outcomes related to fertility. These are: giving birth to a stillborn baby; giving birth to a baby of low birth weight; giving birth to a baby while still a teenager; and giving birth to a baby outside a stable partnership. A proxy for the latter case was a baby whose birth outside marriage was solely registered. To avoid overlap only solely registered births where the mother was aged 20 or over were considered.

The degree of adversity of the live birth outcomes are arguable, but in their different ways these outcomes are not as auspicious as births of normal weight to mothers over 19 with an identified partner. Teenage motherhood is associated with poorer economic and social prospects for the mother and child. ${ }^{10}$ Having a child outside marriage and without a father being identified at registration is not necessarily a disaster, but the chances of a good income are generally low for single mother families.

The Longitudinal Study (LS) is a record linkage study of a sample of the population of England and Wales. The approximately 1\% sample, effectively randomly selected, was initiated at the time of the 1971 census. At any one time there are records of about 500000 living people in England and Wales (the LS members), plus records of ex-members who have died or emigrated. The sample is regularly updated to include new members. Deaths of LS members are traced with the help of the National Health Service Central Register. For this analysis deaths up to the end of 1992 are included. A range of small area statistics are available on the dataset, from which deprivation measures for the ward of residence of the LS member can be calculated. The study is managed by The Office for National Statistics
(ONS) and anonymous data are available to academic researchers, subject to strict confidentiality.

\section{Method}

Only members who were present at the 1981 census and who were aged $10-64$ on census day 1981, are included in any analysis. Residents of institutions and those classified as "permanently sick or disabled" in 1981 are excluded throughout. The various outcomes were defined (see table 1) and the risk of experiencing each outcome before the end of 1992 (or being self classified "ill" at the 1991 census) were estimated by multiple logistic regression models. Models estimate summary risks of the outcome occurring (as odds ratios), stratified by age and north/south geographical zone. North/south zone distinguishes north and east England, and Wales, from south and east England. For mortality models deaths in 1981 or 1982 were excluded to minimise selection effects. Survival was assessed across time periods 1983-87 and 1988-92 and the oldest age group censored to restrict the model to mortality before age 70 . For the fertility related events age ranges and lengths of follow up were tailored as necessary. The teenage birth model had less follow up than others because this could not extend beyond age 19 .

This study looks at all wards in England and Wales that contained an LS member in the relevant age group in 1981. Wards are the constituency for local governement elections. Their average population is around 5500, but this varies considerably. On average they are roughly on the scale that might be called a "neighbourhood", but the boundaries of local communities do not necessarily coincide with 

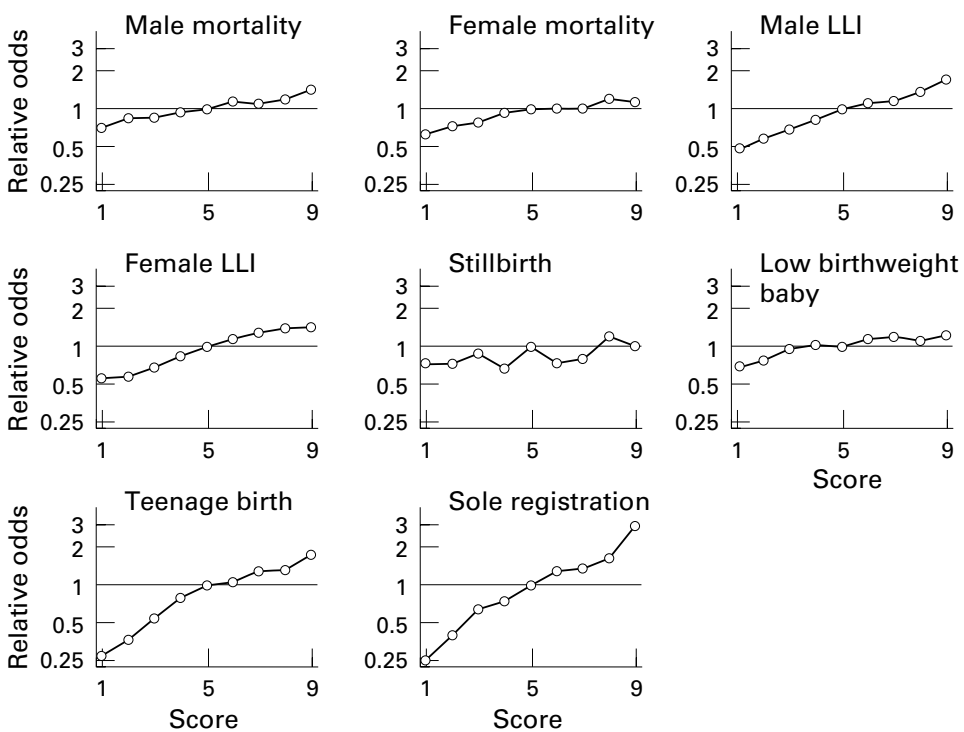

Figure 1 Relative odds of outcome by area deprivation score: gradients adjusted for age and north/south zone (also time period for mortality models).

those of wards. ${ }^{11}$ Deprivation was defined solely by criteria available nationwide from the census, using variables that were also measured for the individual-low social class, unemployment, car access, and home ownership. Apart from our north/south indicator there is no specific information that identifies particular locations. Analysis was performed using the statistical package STATA. Ward identifiers are not disclosed in the LS dataset and multi-level modelling techniques were not possible under data access arrangements. However England and Wales comprises some 9000 wards, each providing a sample of approximately $30 \mathrm{LS}$ members in the selected ages, at least for the mortality analyses. With such wide coverage the effects of clustering were not expected to be influential.

Deprivation was assessed by a "Townsend/Carstairs ${ }^{12}$ like" index of four components; each measured for the ward of
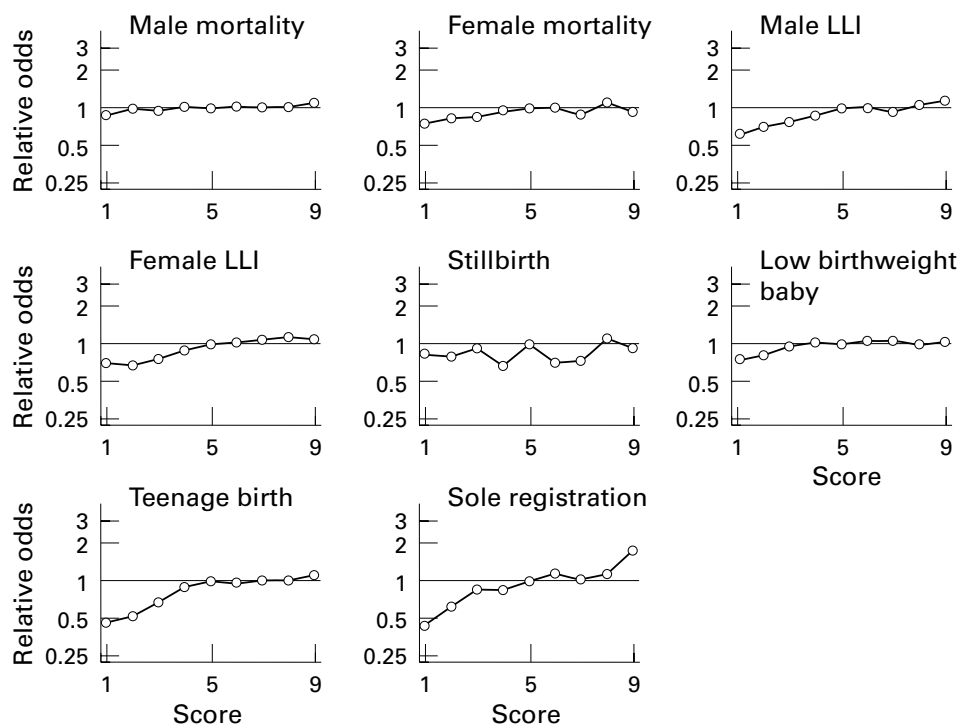

Figure 2 Relative odds of outcome by area deprivation score: gradients additionally adjusted by personal or household circumstances. residence at the 1981 census. These components were: the proportion of the labour force unemployed; proportion of households with no car access; proportion of households not owner occupied, and the proportion of employed men and women in Social Class 4 or 5. A measure of overcrowding was not used because of the increasingly small proportion of dwellings that can be so described. Construction of the index was as described by Townsend et al. ${ }^{13}$ Normal (Z) scores were calculated for each of the four components, after log transformation in the case of proportions unemployed. Some components of the score that registered extreme normal scores for some wards were judiciously recoded; this affected less than $0.1 \%$ of the cases. This process produces transformed components that have comparable metric that allows them to be summed to form a single index.

The resulting index ranged from -8 to +16 , median zero. Higher values indicate more disadvantage. Values were grouped into nine categories of equal band width (not equal case numbers), except for the few $(0.5 \%)$ extreme values that were coded into the top and bottom categories respectively. The resulting score ranged from 1 to 9 (low to high deprivation), and was fairly normally distributed, with some positive skew.

Having derived this measure of area deprivation our analysis strategy was firstly to determine the relation between area deprivation and the various outcomes. Secondly we investigated how far relations with area deprivation reflect the personal or household characteristics of resident individuals; especially characteristics that were counterparts of variables used to construct the deprivation score. The third step was to investigate appropriate interactions of area deprivation and personal circumstance.

Models for teenage births are deliberately simple, not fully controlled by all the personal components of the deprivation score. As the population at risk were very young in 1981 variables connected with the labour market are not included, only those describing the circumstances of their households. Clearly, other important individual level variables are also omitted, such as ethnicity, parent's employment, and the fertility history of the teenager's own mother.

Because the unemployment component of the area deprivation score excludes the economically inactive from the denominator we distinguished the category "housewife/other", in addition to the unemployed, among our range of personal circumstances.

The control for geographical zone is included as our previous work indicated that there were broad regional differences not accounted for by either individual or local circumstances. ${ }^{9}$ These might include the physical or economic climate, cultural factors such as diet, or other aspects of the environment. Water softness seems to be one of them, which has been investigated elsewhere. ${ }^{14}$ Our concern is not to explore these factors here but to acknowledge their existence. The coefficients 
Table 3 Models for various outcomes showing separate gradient parameters for personal terms

\begin{tabular}{|c|c|c|c|c|c|c|c|c|c|c|}
\hline \multirow[b]{2}{*}{ Model } & \multicolumn{2}{|c|}{ Male LLI } & \multicolumn{2}{|c|}{ Female LLI } & \multicolumn{2}{|c|}{ Low birth weight } & \multicolumn{2}{|c|}{ Teenage birth } & \multicolumn{2}{|c|}{ Sole registration } \\
\hline & $O R$ & $p$ & $O R$ & $p$ & $O R$ & $p$ & $O R$ & $p$ & $O R$ & $p$ \\
\hline $\begin{array}{l}\text { Gradient of deprivation score for no } \\
\text { personal deprivation }\end{array}$ & 1.12 & $<0.001$ & 1.08 & $<0.001$ & 1.00 & 0.918 & 1.20 & $<0.001$ & 1.07 & 0.057 \\
\hline Being unemployed & 2.39 & $<0.001$ & 3.11 & $<0.001$ & 1.02 & 0.913 & & & 4.07 & $<0.001$ \\
\hline Gradient term & 0.97 & 0.031 & 0.95 & 0.024 & 1.06 & 0.115 & N/A & & 0.92 & 0.023 \\
\hline Being a housewife ${ }^{\star}$ & & & 1.26 & $<0.001$ & 0.45 & $<0.001$ & & & 0.86 & 0.351 \\
\hline Gradient term & $\mathrm{N} / \mathrm{A}$ & & 1.04 & 0.001 & 1.13 & $<0.001$ & N/A & & 1.08 & 0.017 \\
\hline Low social class & 1.41 & $<0.001$ & 1.19 & 0.004 & 0.87 & 0.338 & & & 1.48 & 0.053 \\
\hline Gradient term & 0.97 & 0.021 & 1.00 & 0.820 & 1.03 & 0.366 & N/A & & 0.99 & 0.737 \\
\hline Not owner occupier & 1.52 & $<0.001$ & 1.52 & $<0.001$ & 1.17 & 0.126 & 3.06 & $<0.001$ & 1.76 & $<0.001$ \\
\hline Gradient term & 0.97 & 0.001 & 0.97 & 0.006 & 0.99 & 0.778 & 0.94 & 0.003 & 1.05 & 0.122 \\
\hline No car access & 1.50 & $<0.001$ & 1.66 & $<0.001$ & 1.30 & 0.026 & 2.31 & $<0.001$ & 1.85 & $<0.001$ \\
\hline Gradient term & 0.98 & 0.129 & 0.96 & $<0.001$ & 0.97 & 0.269 & 0.93 & 0.001 & 0.99 & 0.862 \\
\hline$\chi^{2}$ improvement for model $\dagger$ & $42(5)$ & $<0.001$ & $58(5)$ & $<0.001$ & $74(5)$ & $<0.001$ & $30(2)$ & $<0.001$ & $23(5)$ & $<0.001$ \\
\hline
\end{tabular}

Model details: All models adjusted for age and north/south zone. ${ }^{\star}$ Housewife/other category is mostly housewives for females datasets. $\dagger$ Improvement is for model with separate slope parameters for all personal terms, compared with model 2 of table 2 .

are not reported or discussed but for mortality the increased risk from being in the north was approximately $12 \%(\mathrm{p}<0.001)$ for both men and women.

\section{Results}

Figure 1 shows the "unadjusted" relations between area deprivation score in 1981 and the chosen outcomes. "Unadjusted" slopes are in fact adjusted for age, geographic zone, and time period in the case of mortality. A positive gradient is apparent for all outcomes except stillbirth; the more deprived the area the greater the chance of an adverse outcome. This gradient is near linear, although the linearity for female mortality is not as clear as for men. A quadratic term included in the regression models with the deprivation score made little overall difference to interpretation of the deprivation effect and we therefore proceeded assuming linearity.

Table 2 , model 1 , shows how odds ratios of each outcome increase per unit of the area deprivation score. To give some idea of relative magnitude of the "deprivation effect" between the outcomes we have also shown the relative odds, according to our model, for residing in the most highly deprived areas compared with the least deprived.

The "unadjusted" deprivation gradients shown in figure 1 are particularly marked for sole registration and teenage motherhood, and for LLI. The deprivation gradient is shallower for mortality and low birth weight, and indeterminate for stillbirth. This suggests a stronger association with outcomes where a considerable social dimension could be construed, than those which are more directly physiologically determined.

Table 2, model 2, and figure 2 also show the influence of personal factors on the deprivation effect. Leaving stillbirths aside as inconclusive, all models show attenuation of the deprivation gradient when personal factors are known. However the parameters of the area deprivation score remain significant. Closer inspection of figure 2 shows more flattening in areas of higher deprivation. The teenage birth model most clearly demonstrates this-despite the simplicity of the model-the personal/ household factors outweigh the area deprivation in areas of above average deprivation, while the slope remains positive across less deprived wards.

To capture this feature separate slopes were estimated for area deprivation scores of above 4 , and 4 and below, by means of an interaction term. These are shown in table 2, panel 3 . Slopes for the more deprived areas are reduced to near unity for mortality, low birth weight, and teenage births. They are markedly attenuated for LLI. The slope for sole registration stays strongly positive; influenced by the relatively high proportion of sole registrations in the highest deprived areas (see fig 2), even though this actually represents very few households.

Further interactions were specified between the area score and each individual characteristic to test the hypothesis that the unhealthy consequences of poverty would be intensified for those who live in "poor places". Table 3 shows the results. There were no significant interactions for mortality models so these are omitted (as is the stillbirth model).

In table 3 the term for the specified personal deprivation gives the shift in risk for those who experience it. The gradient term gives the relative gradient of the deprivation score, for those who experience the specified personal deprivation, compared with the gradient for those who do not. The terms are multiplicative, a gradient term of less than unity suggesting that the gradient for the deprivation score is shallower for those experiencing the personal deprivation. In this latter case the gradients for the personally deprived and the personally non-deprived are not only separated, but also not parallel-with the difference in risk being wider in less deprived areas.

Not all interactions are well determined but an overall picture is apparent. There is general statistical improvement for the non-mortality models. In most cases the individual disadvantage raises the overall chances of the adverse outcome, while the gradient term for such personally deprived people is less than one, indicating a gradient less steep than for the personally non-deprived. So for most specified disadvantages the differential between deprived and non-deprived persons is wider in less deprived places. Personal deprivation is not compounded by residence in a deprived place (beyond the multiplicative main effects), in fact 
the reverse is suggested. The significant exception to this finding is the situation for housewives-not necessarily a personal disadvantage. Their gradients against area deprivation are actually steeper than for nonhousewives, which suggests that housewives in poor places do suffer somewhat from their location. Housewives appear considerably more at risk for long term illness than those working. Although selection must surely account in part for this result, it is not clear that there would be much of a geographical selection process in operation. The risks of low birth weight and sole registration is lower for housewives: this could reflect the lower proportion of first births among births to housewives.

\section{Discussion}

Our main finding is to confirm that ecological associations of various adverse outcomes with a census based indicator of area deprivation are largely, if not entirely, accounted for by the individual level measures of the same indicators. Whatever contextual factors may be influencing health and the fertility outcomes, they are not well identified by census indicators of social composition-after a modest general difference between the north and the south of the country has been allowed for. We have not been able to test whether modifying the boundaries would uncover better defined neighbourhood effects. ${ }^{15}$ Figure 2 shows a tendency for adjustment by personal factors to be particularly effective in accounting for the ecological associations of figure 1 in the more deprived wards. This could mean that contextual effects are greater between more affluent areas, but it is more likely that the index, designed to pick up "deprivation" does not differentiate well between grades of affluence.

As long as the focus is on the problems of the poorer areas, this failing is of little relevance. The hypothesis that poor areas compound the disadvantages of poor people found some support in a multi-level analysis of the Health and Lifestyle Survey. ${ }^{16}$ It was tested here by including interactions of the area deprivation score and individual circumstances. In contrast with the hypothesis of area deprivation intensifying disadvantage we found that the impact of individual disadvantage was generally greater in more affluent areas, although the effects are not strong. A possible interpretation is that relative deprivation is harder to bear, or that adjustment to adversity is easier in a community where that adversity is more prevalent. However women classified as housewives did seem to fare worse in more deprived areas.

For outcomes excepting sole registration of births and LLI, it seems that those individual factors we do include largely explain risk associated with residence in the more deprived areas. Even for sole registration and LLI there is evidence (fig 2) of attenuation of deprivation gradient across more deprived wards, but it is possible that a contextual effect remains.

There has recently been similar work, using data from the Sample of Anonymysed Records, on the incidence of limiting longstanding illness in $1991 .{ }^{17}$ This also finds a dominant
KEY POINTS

- Census based measures of local area deprivation can help identify not only mortality differentials but a variety of other poor outcomes, some involving the next generation.

- Teenage pregnancy and single registered births are particularly sensitive to the social profile of the locality.

- The role of area in the explanation of outcomes varies but is, at best, secondary. The role of personal circumstances is overriding.

- There is little evidence that residence in a deprived area compounds adverse outcomes for those already personally deprived. The opposite may be true for some groups.

influence of individual factors, but a significant influence of geographical context too. This was detected by using the technique of multi-level modelling to capture unobserved healthiness of districts, and by measuring variables at the community level that were not included at the individual level. Thus, while contextual phenomena may be detected using more complex methods, and more local information, these methods confirm the dominant role of individual disadvantage when compared with the relatively blunt and parsimonious ecological instrument considered here.

Our finding that the level of deprivation in an area has a stronger association with "social" rather than "physiological" outcomes makes sense. The idea that there may indeed be contextual influences (peer norms) is also more plausible for these outcomes. The social component of illness is more pronounced than that in mortality - mortality differentials would seem to understate health inequalities. Why no effect - of area or individual characteristics - is apparent for stillbirths, when it is for low birthweight babies and for adult mortality, is an intriguing question. It may be that stillbirth is a singularly random event (it is certainly rare), or that antenatal care has already selected out most of these events in the form of earlier inductions/terminations.

In conclusion we have repeatedly found that personal rather than area disadvantages dominate the statistical explanation of adverse outcomes, in fertility as well as health and mortality. This confirms the association of poor life chances with poor socioeconomic circumstances. The role of place in these particular processes of poverty and social disadvantage seems to be, at best, secondary.

We have found indications that individual deprivation leads not only to the shortening of lives, but to the inter-generational transmission of social and economic disadvantage through early childbearing. Much of these processes are played out in "poor places", as identified by census indicators of deprivation, but individual disadvantages have adverse, and possibly more intense, long term consequences in other places too. 
In general there does not seem to be any evidence of residence in deprived areas compounding personal disadvantage and further increasing risk of adverse outcome. If anything the reverse is true but the effect is not strong. An exception to this, worthy of further study, is for those women who classify themselves as housewives. For them, residence in deprived areas does seem additionally detrimental.

Where contextual effects do exist they are probably location specific, clear to those with local knowledge but unlikely to be easily identified by routine use of aggregate census indicators. In general, places where disadvantaged people congregate are places where disadvantaged lives are lived out, of itself a reason to prioritise the improvement of services and opportunities.

This research is part of a wider programme entitled "Deprivation Indicators: Stability and Reliability over Locality and Lifecycle." The permission of ONS to use the Longitudinal Study is gratefully acknowleged, as is help provided by staff of the Social Statistics Research Unit, City University. The views presented in this paper are not necessarily those of ONS

Funding: this study was funded by the Economic and Social Research Council, under grant No H507255130, as part of thei Census Programme.

Conflicts of interest: none.

1 Carstairs V, Morris R. Deprivation and mortality: an alternative to social class? Community Med 1989;11:21019.

2 Carstairs V. Deprivation indices: their interpretation and use in relation to health. F Epidemiol Community Health 1995;49 (suppl 2):S3-8.
3 Curtis S. Geographical perspectives on poverty and health policy in different parts of the UK. In: Philo C, ed. Off the policy in different parts of the UK. In: Philo C, ed. Off the map: the social geography

4 Eames M, Ben-Shlomo Y, Marmot M. Social deprivation and premature mortality: regional comparison across Engand. BMF 1993;307:1097-102.

5 Davies H, Joshi H, Clarke L. Is it cash the deprived are short of? Fournal of the Royal Statistical Society: Series A 1997;160 (part 1):107-26

6 McCormick J, Philo C. Where is poverty? The hidden geography of poverty in the United Kingdom. In: Philo C, ed. London: CPAG, 1995:1-22.

7 Mohan J. Missing the boat: poverty, debt and unemployment in the South East. In: Philo C, ed. Off the map: the social geography of poverty in the UK. London: CPAG, 1995:

8 Macintyre S, MacIver S, Sooman A. Area, class and health: should we be focusing on places or people? fournal of Social Policy 1993;22:213-34.

9 Sloggett A, Joshi H. Higher mortality in deprived areas: community or personal disadvantage? BMF 1994;309: 1471-4.

10 Macran S, Joshi H, Dex S. Employment after childbearing: a survival analysis. Work Employment and Society 1996;10: 273-96.

11 Green A. The Geography of poverty and wealth. Coventry: Institute for Employment Research, Warwick University, 1994.

12 Morris R, Carstairs V. Which deprivation? A comparison of selected deprivation indexes. F Pub Health Med 1991;13: 318-26.

13 Townsend P, Phillimore P, Beattie A. Health and deprivation. London: Routledge, 1989.

14 Sloggett A, Downing A. The effects of total water hardness, smoke particles and sulphur dioxide levels on mortality in urban areas of England and Wales. Geographia Polonica 1995;64:177-86.

15 Openshaw S. The modifiable areal unit problem. Norwich: Geo Books, 1994

16 Humphreys K, Carr-Hill R. Area variations in health outcomes: artefact or ecology. Int f Epidemiol 1991;20:2518.

17 Shouls S, Congdon P, Curtis S. Modelling inequality in reported long-term illness in the UK: combining individual and area characteristics. $\mathcal{F}$ Epidemiol Community Health 1996;50:366-76. 